\title{
BMJ Open Existential distress in patients with advanced cancer and their caregivers: study protocol of a longitudinal cohort study
}

\author{
Rebecca Philipp (D) , ${ }^{1}$ Anna Kalender, ${ }^{1,2}$ Martin Härter (D) , ${ }^{1}$ \\ Carsten Bokemeyer (D) , ${ }^{2}$ Karin Oechsle (D) , ${ }^{3}$ Uwe Koch, ${ }^{1}$ Sigrun Vehling (D) ${ }^{1,2}$
}

To cite: Philipp R, Kalender A, Härter M, et al. Existential distress in patients with advanced cancer and their caregivers: study protocol of a longitudinal cohort study. BMJ Open 2021;11:e046351. doi:10.1136/ bmjopen-2020-046351

- Prepublication history for this paper is available online. To view these files, please visit the journal online (http://dx.doi org/10.1136/bmjopen-2020046351).

Received 28 0ctober 2020 Revised 18 February 2021 Accepted 17 March 2021

Check for updates

(C) Author(s) (or their employer(s)) 2021. Re-use permitted under CC BY-NC. No commercial re-use. See rights and permissions. Published by BMJ.

${ }^{1}$ Department of Medical Psychology, University Medical Center Hamburg-Eppendorf, Hamburg, Germany

${ }^{2}$ Department of Oncology, Hematology, and Bone Marrow Transplantation with Section of Pneumology, University Medical Center Hamburg-Eppendorf, Hamburg, Germany

${ }^{3}$ Department of Oncology, Hematology, and Bone Marrow Transplantation with Section of Pneumology, Palliative Care Unit, University Medical Center Hamburg-Eppendorf, Hamburg, Germany

Correspondence to

Rebecca Philipp;

r.philipp@uke.de

\section{ABSTRACT}

Introduction At the end of life, patients with advanced cancer and their informal caregivers may confront multiple existential concerns. Despite the strong potential to alleviate existential distress through psychosocial interventions, existential distress and its impact on healthcare outcomes have not yet been studied systematically. We aim to investigate the frequency, longitudinal trajectory and predictive impact of existential distress on end-of-life outcomes. We further aim to determine patients' and caregivers' specific need for and utilisation of psychosocial support for existential distress. Methods This longitudinal cohort study will consecutively recruit 500 patients with advanced cancer and 500 caregivers from oncological outpatient and inpatient clinics. Participants will complete self-report questionnaires (sociodemographic and disease-related characteristics, existential distress, end-of-life outcomes, resources and support needs) at five points of assessment (at baseline and after 3, 6, 9 and 12 months). At baseline and 6-month follow-up, we will conduct structured diagnostic interviews to assess mental disorders. Statistical analyses will include descriptive statistics to determine the prevalence of existential distress, mental disorders and end-of-life outcomes; multiple linear and logistic regression analyses to calculate the predictive impact of existential distress on end-of-life outcomes; and growth mixture models to analyse longitudinal trajectories of existential distress.

Discussion This study will provide comprehensive knowledge about patients' and caregivers' existential concerns. The longitudinal empirical data will allow for conclusions concerning the frequency and course of existential distress throughout 1 year. This important extension of existing cross-sectional research will contribute to further develop targeted psychosocial interventions. Profiles of existential distress may be applied by clinicians from multiple professions and help to address existential concerns effectively.

Ethics and dissemination The study was approved by the institutional research ethics committee (reference number LPEK-0177). Results will be presented at scientific conferences and published in peer-reviewed journals. Other forms of dissemination will include sharing results on the psychometric properties of the structured demoralisation interview with international research
Strengths and limitations of this study

- Longitudinal empirical data will allow for conclusions concerning frequency and course of existential distress in patients and caregivers throughout 1 year.

- Recruitment strategy allows enrolment of a large, heterogeneous sample of patients with advanced cancer from a range of clinics and treatment facilities.

- Profiles of existential distress may be applied by clinicians from multiple professions and help to address existential concerns effectively.

- Extensive assessment of psychological distress in a potentially highly distressed and understudied sample.

- Potentially high dropout rates due to patients' physical decline or death within the study period.

groups and communication with healthcare professionals providing psychosocial treatment for patients and caregivers. Following scientific standards, our progress will be regularly updated on ClinicalTrials.gov. Trial registration number NCT04600206.

\section{INTRODUCTION}

In Germany, more than 230000 individuals die from cancer each year. Due to an ageing population and improvement in life-prolonging anticancer treatments, the number of patients and caregivers who face the existential consequences of living with advanced incurable cancer will strongly increase over the next years. ${ }^{12}$ In about onethird of patients with cancer, multiple sources of distress are associated with increased levels of depression and anxiety. ${ }^{34}$ Informal caregivers are confronted with often conflicting demands of caring for a severely ill loved one and maintaining a focus on their own needs, resulting in high levels of psychological distress. ${ }^{5-8}$ Although the existential domain 


\section{Existential distress of patients and caregivers in life-threatening illness}

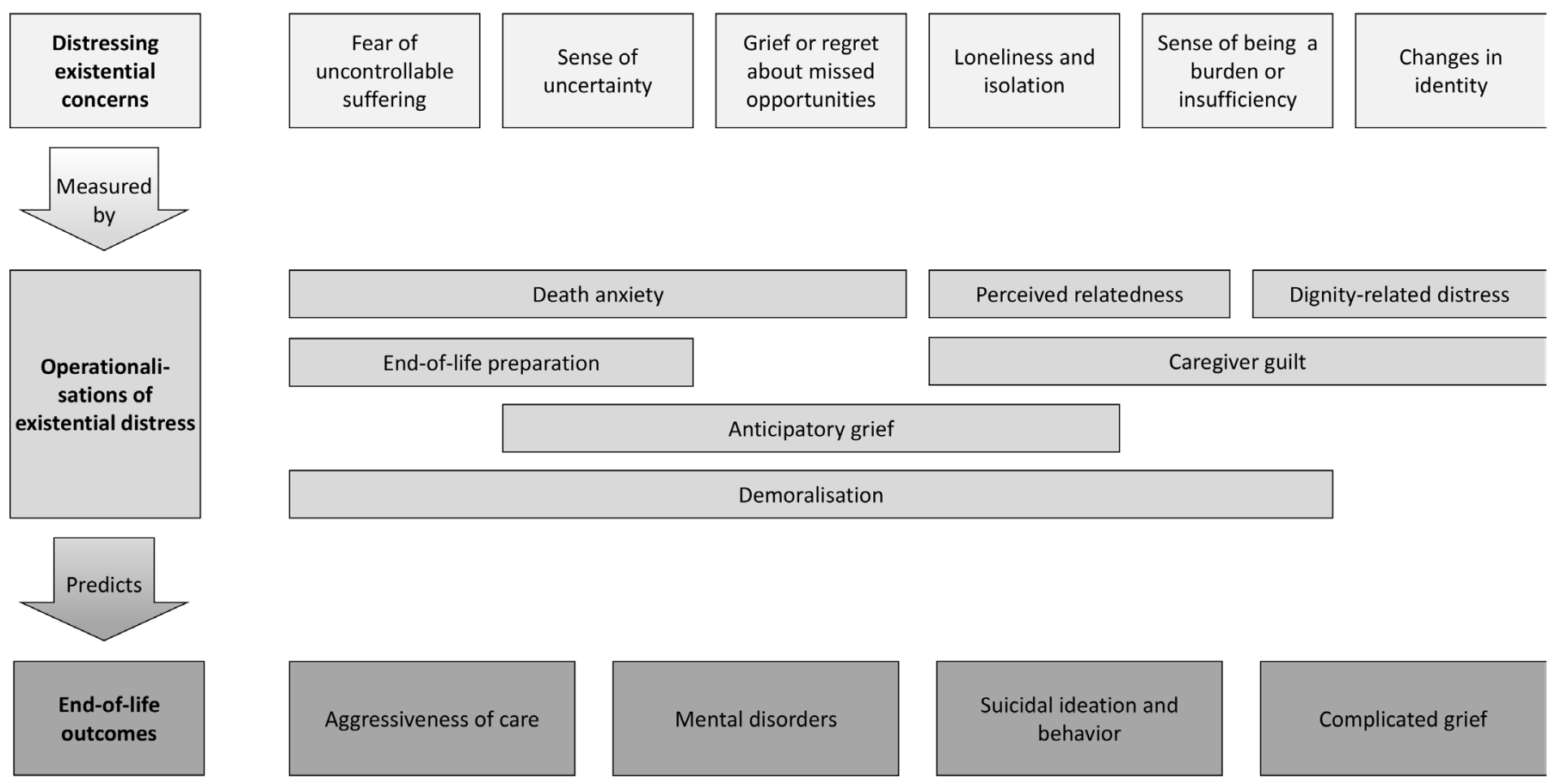

Figure 1 Research model of existential distress in life-threatening illness. The figure shows a proposed taxonomy of existential concerns and their operationalisation by existential distress concepts, as well as the potential association of these concepts with end-of-life outcomes among patients with advanced cancer and their caregivers.

of suffering has long been incorporated into a biopsychosocial perspective in advanced cancer and palliative care, ${ }^{9-11}$ existential distress has received little attention in systematic quantitative or prospective research in these populations.

Existential distress refers to a distinct domain of cancerrelated distress. It may occur alongside other forms of distress but can also arise independently, even when physical pain is treated, social support is available and no mental disorder is present. ${ }^{12} 13$ Due to the fundamental losses and changes advanced cancer can cause, emotional pain and despair may be experienced as 'existential', similar to the distress described by existential philosophers, which arises from the finitude of life and the ramifications of existence. ${ }^{14}$ Based on earlier reviews and conceptual literature, ${ }^{15-20}$ we propose a taxonomy that integrates different existential concerns among patients and caregivers and links them to operationalisations of existential distress (figure 1, first and middle part). According to this taxonomy, frequently described existential concerns including fear of what will happen at death, uncertainty, unpreparedness, a sense of being a burden to others or a sense of profound loneliness can be systematically measured by clearly defined concepts. Operationalisations of existential distress concepts in patients with cancer include for example death anxiety, ${ }^{21} 22$ demoralisation $^{23}$ and dignity-related concerns ${ }^{24}{ }^{25}$ (figure 1, middle part). Figure 1 (middle and lower part) further illustrates the research model for association of these concepts with end-of-life outcomes.

Demoralisation is defined by lowered morale and a perceived incapacity to cope that can become associated with a sense of helplessness and failure and a loss of selfworth, hope and meaning in life. ${ }^{26}$ Systematic reviews indicate that $20 \%$ of patients with advanced cancer experience demoralisation. ${ }^{27}{ }^{28}$ Death anxiety refers to distress due to a shortened life expectancy, fears about uncontrollable suffering, worry about the impact of one's death on others and regret about missed opportunities in life. ${ }^{21} 22$ A study in 382 outpatients with advanced cancer found significant death anxiety in $27 \%$ of the study participants. ${ }^{29}$ Dignity-related concerns, such as perceived burdensomeness, were reported by up to $23 \%$ of the patients, ${ }^{3031}$ while $8 \%$ experienced a significantly impaired sense of dignity. ${ }^{25}$ Other related categories of existential concerns include unpreparedness at the end of life $(31 \%),{ }^{32}$ loss of control $(16 \%)$, isolation $(22 \%)$, uncompleted life tasks $(7 \%)$ and loss of continuity (loss of role, loss of enjoyable activity and loss of being oneself) $(10 \%){ }^{33}$

Especially spouses of patients with cancer may experience identity-related existential concerns $(20 \%) .{ }^{34}$ This may include role strain through the adoption of the caregiver role and associated changes in the relationship. ${ }^{35}$ Caregivers may experience a change in their identity as a result of the extensive impact of caregiving on everyday life and the exertion of other important roles. ${ }^{35} 36$ They 
may also suffer from the patient's perceived loss of identity. ${ }^{37}$

However, to date there is only limited research about the occurrence of existential distress in caregivers. While both patients and caregivers may be affected by demoralisation and death anxiety, caregivers also face unique existential concerns including guilt, anticipatory grief ${ }^{53}$ or despair about how to go on after their partner's death. ${ }^{39}$ They often feel incompetent and unprepared for the task of caring for a loved one, which may lead to feelings of insufficiency and guilt for not providing appropriate care. ${ }^{40}$ At the same time, caregivers often experience the pressure of maintaining hope and a positive attitude, preventing them from discussing own concerns. ${ }^{41}$ Given this double challenge, caregivers may feel isolated and lonely. Whereas some couples manage to renegotiate roles and find ways to communicate about these issues, patients also tend to feel alienated by their caregivers' denial and avoidance of conflict. ${ }^{42}$ This lack of perceived relatedness in close relationships is a common source of existential distress for patients and caregivers. ${ }^{43}$ Moreover, difficulties in coping with existential concerns have been associated with complicated grief. ${ }^{45}{ }^{45}$ Yet little is known on the extent to which caregivers are affected by their own existential fears and hopelessness. ${ }^{46}$

Among patients with advanced cancer, cross-sectional studies do not only suggest a positive association between demoralisation and an increased risk for adjustment, depressive and anxiety disorders, they also found positive associations between existential distress and suicidal ideation or the desire for hastened death. ${ }^{47-49}$ In the context of legalising physician-assisted suicide in Canada, Li $e t a \tilde{l}^{0}$ observed existential distress to be an important motive for these requests. A rare longitudinal study found an increase of existential distress over time. ${ }^{51}$ Moreover, existential issues may contribute to receiving aggressive treatments in the last weeks of life. ${ }^{52} 53$ Studies also indicate a positive association of religious coping with aggressive treatment at the end of life. ${ }^{54}$ It is possible that existential distress is linked to a form of coping that interferes with prognostic awareness and timely end-oflife discussions. There is growing evidence that the ability to maintain a sense of meaning, acceptance and use of approach-oriented coping may contribute to better endof-life outcomes. ${ }^{567}$ However, the role of death anxiety, lack of preparedness, a strong hope for cure and incongruence of patient and caregiver acceptance for end-oflife care outcomes is currently unclear. ${ }^{58}$ Although the impact of caregiver existential distress on patient end-oflife outcomes may be partially mediated by patient existential distress, a relevant impact may be expected. ${ }^{7}$

\section{Objectives}

Existential distress may have profound consequences for healthcare outcomes of patients and their caregivers at the end of life. Despite their strong potential for alleviation through psychosocial interventions, clinicians struggle to recognise and address existential concerns. ${ }^{5960}$
In the shadow of prominent debates about autonomy at the end of life, research has fallen short of understanding the multifaceted factors that underlie existential distress. Due to the lack of systematic longitudinal studies, there is limited knowledge about the occurrence of existential distress, how it evolves over time and its prospective impact on important end-of-life outcomes. Moreover, it is of substantial clinical relevance to assess caregivers' existential issues quantitatively, which have been predominantly studied qualitatively so far.

This study will systematically assess existential distress and investigate its impact on patient-relevant and caregiver-relevant outcomes at the end of life. Therefore, we aim:

1. To investigate the frequency and longitudinal trajectory of existential distress in patients with advanced cancer and their caregivers.

2. To examine the predictive impact of existential distress on patient-relevant and caregiver-relevant end-of-life outcomes.

3. To determine patients' and caregivers' specific need for and utilisation of psychosocial support with respect to existential concerns.

4. To explore typical profiles of existential distress in patients and caregivers.

\section{METHODS AND ANALYSIS}

\section{Study design}

Starting October 2020, we will conduct a longitudinal cohort study over a period of 12 months. This study period includes five points of assessment at baseline (T1), 3 months (T2), 6 months (T3), 9 months (T4) and 12 months (T5). The study was registered at ClinicalTrials. gov.

\section{Participants and recruitment}

We will consecutively recruit 500 patients and 500 informal caregivers from outpatient and inpatient clinics including oncological and palliative care units at the University Cancer Center Hamburg (UCCH, University Medical Center Hamburg and affiliated hospitals located in the Hamburg metropolitan region). Eligible patients are at least 18 years old and diagnosed with advanced cancer as defined by Union for International Cancer Control (UICC) stage IV solid tumours. Eligible caregivers (spouse or partner, family member or close friend) are at least 18 years old. Assessment will include patients with advanced cancer and caregivers across all phases of advanced disease from diagnosis to terminal stages to reflect a cross-section of treatment settings, tumour entities and time since diagnosis. Recruitment is not limited to patient-caregiver dyads; patients and caregivers can participate individually. Exclusion criteria for patients and caregivers are severe cognitive or physical impairment and insufficient ability to speak German to give informed consent and to complete the self-report questionnaires. 


\section{Procedures}

Patients and caregivers will be approached on occasion of treatment at the respective clinic by trained research assistants. We will obtain written informed consent from patients and caregivers prior to participation. Participants may withdraw informed consent at any time. Patients and caregivers will complete paper-pencil self-report questionnaires to measure existential distress and respective support needs at each point of assessment. At baseline (T1) and after 6 months (T3), we will conduct structured diagnostic interviews with patients and caregivers face to face or via telephone to assess mental disorders.

We will assess sociodemographic characteristics of patients and caregivers (age, gender, education and socioeconomic data) using a standardised self-report questionnaire. We will extract disease and medical care-related characteristics (tumour entity, tumour stage, time since diagnosis and anticancer and psychopharmacological treatments) from patients' medical charts. We will further review patients' medical charts regularly for record of deceased patients and extraction of medical care data. For postbereavement assessment, we will approach caregivers of deceased patients 3 months after a patient's death. We will conduct follow-up assessments via mail, telephone or on patients' and caregivers' appointments for medical treatment at the cancer centres. For nonresponder analyses, we will collect basic demographic and medical data from non-participants on a voluntary basis. The COVID-19 pandemic has led to limited access of caregivers to oncological treatment facilities. We will adapt the recruitment strategy accordingly and approach caregivers via phone on the patient's approval.

\section{Measures}

Table 1 shows self-report questionnaires and observerrated instruments that will be completed by patients, caregivers or both.

\section{Existential distress}

We will assess death anxiety in patients and caregivers using the Death and Dying Distress Scale. ${ }^{21}{ }^{22}$ The 15-item scale measures clinically significant distress with regard to concerns surrounding the patient's death. This includes psychosocial and existential concerns about missed opportunities and the loss of time, past regrets and uncertainty about the future and the burden of death on others. It also measures practical concerns about the process of dying, including fears about dying alone or with suffering or worries about its timing. Items are scored on a 6-point Likert scale ranging from 0 (no distress) to 5 (extreme distress). The sum score ranges from 0 to 75 ; scores $\geq 45$ indicate moderate to high levels death anxiety. A modified version of the scale validated in German patients with cancer showed excellent internal consistency (Cronbach's $\alpha=0.91){ }^{61}$ The caregiver version (unpublished) will be validated in the current study ( $\mathrm{C}$ Lo, personal communication, May 2020).
We will assess demoralisation in patients and caregivers using the Demoralisation Scale-II. ${ }^{62}{ }^{63}$ The 16 -item revised scale measures feelings of hopelessness and helplessness and loss of meaning and purpose on two subscales (Meaning and Purpose, Distress and Coping Ability). Items are scored on a 3-point Likert scale ranging from 0 (never) to 2 (often). Sum scores range from 0 to 32 for the total scale and from 0 to 16 for the subscales. The subscales and the total scale (Cronbach's $\alpha=0.89$ ) show good internal consistency. ${ }^{62}$ The original scale ${ }^{64}$ was validated in German patients with cancer and showed good internal consistency (Cronbach's $\alpha=0.84$ ). ${ }^{65}$ Although the scale is mostly used in patients with cancer, it has been validated in different non-cancer populations and is applicable to caregivers.

We will assess perceived relatedness for patients and caregivers using the subscales Dependence and Relatedness of the Depressive Experiences Questionnaire. ${ }^{66}$ The 18-item and 8-item scales are distinct aspects of an overall Dependency factor. They measure interpersonal issues like feelings of helplessness, fear of rejection and feelings of loneliness due to disruption in a relationship. Items are scored on a 7-point Likert scale ranging from 1 (disagree) to 7 (agree). According to the procedure described by Blatt et $a l,{ }^{68}$ we calculate scores based on the factor scores derived from a confirmatory factor analysis. The authors provided us with a syntax for SPSS (D Zuroff, personal communication, May 2020). The German version was validated in clinical and non-clinical samples and showed acceptable to good internal consistency (Cronbach's $\alpha=0.74-0.83) .^{69} 70$

We will assess end-of-life-preparation and adjustment processes in patients and caregivers using the Loss Orientation and Life Engagement in Advanced Cancer Scale. ${ }^{71}$ The 20-item scale measures preoccupation with death and dying, engagement in personally meaningful activities and coping efforts including end-of-life preparation, distraction and hoping for a positive outcome. Items are scored on a 5-point Likert scale ranging from 0 (not at all) to 4 (nearly all the time). High scores indicate high levels of loss orientation, life engagement and coping efforts, respectively. The pilot version of the scale showed good internal consistency (Cronbach's $\alpha=0.80-0.88$ ). A parallel caregiver version (unpublished) will be validated in the present study.

We will assess dignity-related distress in patients using the Sense of Dignity Item. ${ }^{25}$ The item measures subjective loss of dignity on a 7-point Likert scale ranging from 0 (no sense of loss of dignity) to 6 (extreme sense of loss of dignity). A score $>3$ indicates a fractured sense of dignity. Furthermore, we will assess dignity-related and identity-related concerns using the Patient Dignity Inventory. ${ }^{72}$ The 25 -item scale measures the loss of sense of dignity in patients with terminal illness. For our purposes, we will only use the subscales assessing Physical Symptom Distress and Body Image and Loss of Autonomy, according to the validated German version. ${ }^{73}$ Items are scored on a 5-point Likert scale ranging from 1 (not a problem) to 5 (overwhelming 
Table 1 Self-report questionnaires and observer-rated instruments

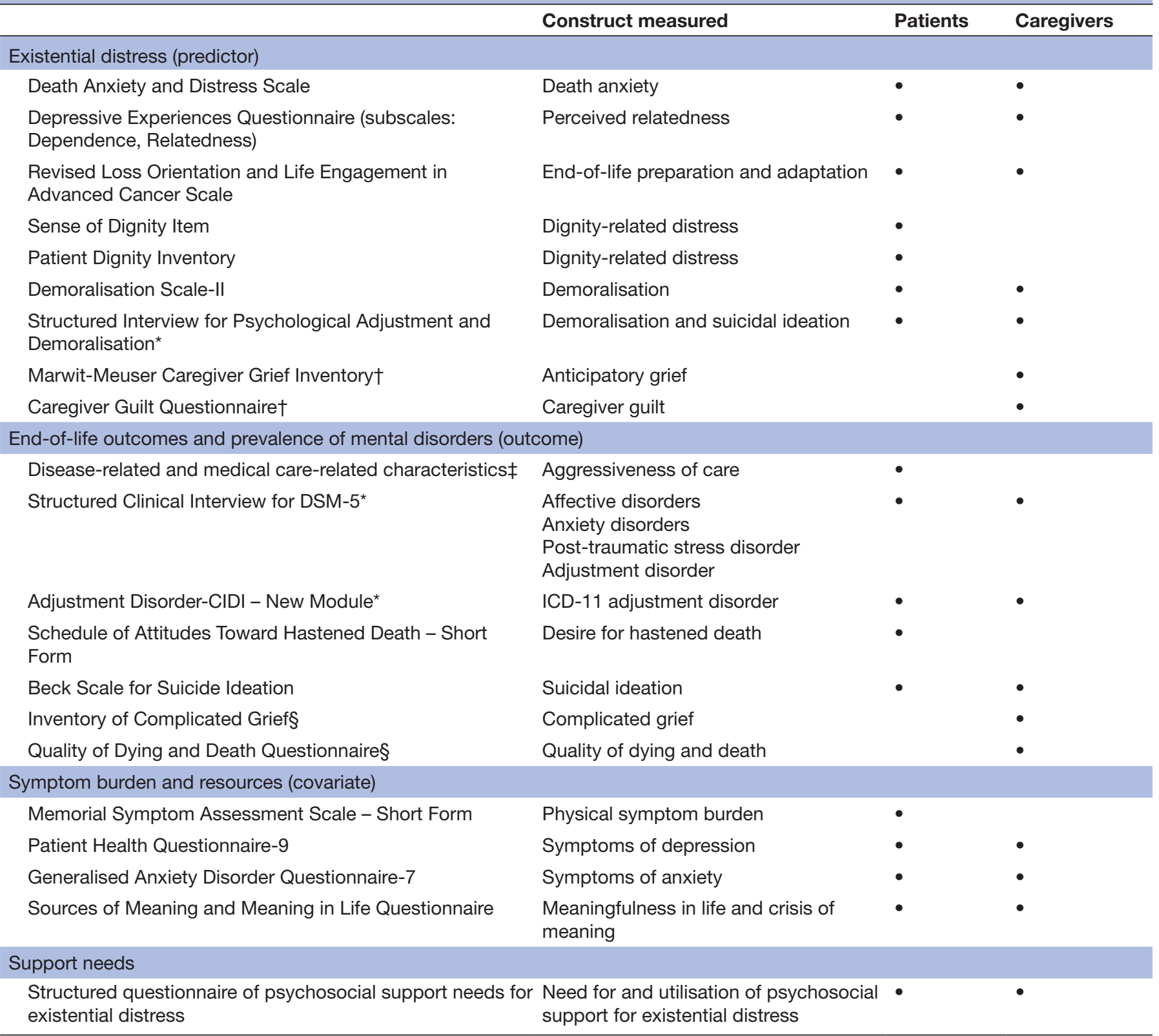

*Observer-rated interview.

†Not assessed after the patient's death.

$\ddagger$ Assessed via medical chart review.

$\S$ Assessed after the patient's death only.

CIDI, Composite International Diagnostic Interview; ICD-11, International Classification of Diseases-11.

problem). Scores $\geq 3$ indicate that a relevant problem is experienced. The German version of the scale showed excellent internal consistency (Cronbach's $\alpha=0.96){ }^{73}$

We will assess demoralisation in patients and caregivers using the Structured Interview for Psychological Adjustment and Demoralisation developed by Kissane and colleagues (I Bobevski and D Kissane, 2019, Structured Interview for Psychological Adjustment and Demoralisation, unpublished clinical interview). The 36 -item interview measures participants' sense of coping with any stressful event, including cancer and its treatment, with regard to level of avoidance, symptoms of demoralisation, preoccupation, value of life and functional impairment. It also assesses suicidal ideation. Items are answered with yes or no. The diagnostic algorithm is based on the proposed criteria for adjustment disorder with demoralisation. ${ }^{23} 74$

As part of the structured interview, patients' and caregivers' goals of care and recall of goals of care discussions ${ }^{75}$ with physicians will be assessed.

We will assess anticipatory grief in caregivers using the short version of the Marwit-Meuser Caregiver Grief Inventory. ${ }^{76}$ The 18 -item scale measures predeath grief on the subscales Personal Sacrifice and Burden, Heartfelt Sadness and Longing, and Worry and Felt Isolation. Items are scored on a 
5-point Likert scale ranging from 1 (strongly disagree) to 5 (strongly agree). Three items, which referred to aspects specific to dementia, were adapted to cancer populations (S Marwit, personal communication, June 2020). The total sum score ranges from 0 to 90 . High scores indicate a higher level of grief level. Originally developed for caregivers of patients with Alzheimer's disease, its psychometric properties have been confirmed among caregivers of patients with cancer. The total scale and the subscales showed good to excellent internal consistency (Cronbach's $\alpha=0.80-0.90$ ).

We will assess guilt in caregivers using the Caregiver Guilt Questionnaire. ${ }^{77}$ The 22-item scale measures aspects of guilt experienced by caregivers on the subscales guilt about doing wrong by the care recipient, uilt about not rising to the occasion as caregivers, guilt about self-care, guilt about neglecting other relatives and guilt about having negative feelings towards other people. Items are scored on a 5-point Likert scale ranging from 0 (never) to 4 (always or most always). The total sum score ranges from 0 to 88 . Higher scores indicate greater guilt. The total scale and the subscales showed acceptable to good internal consistency (Cronbach's $\alpha=0.63$ to 0.89 ).

\section{End-of-life outcomes and prevalence of mental disorders}

Aggressiveness of care will be assessed by receipt of chemotherapy in the last 2 weeks of life, and emergency hospital admissions or intensive care treatment during the last month of life ${ }^{78}$ Information will be obtained from medical chart reviews for deceased patients. Furthermore, we will document the uptake and duration of specialised palliative care or hospice services received and place of death. We will further assess documentation of end-of-life care discussions as well as medical orders for life-sustaining treatment in the electronic health record.

We will assess the prevalence of mental disordersincluding affective and anxiety disorders, post-traumatic stress disorder and adjustment disorder in patients and caregivers using the Structured Clinical Interview for the Diagnostic and Statistical Manual of Mental Disorders (DSM-5). ${ }^{79}$ The semistructured clinical interview measures mental disorders according to the DSM- $5 .{ }^{80}$ The German version showed acceptable internal consistency (Cronbach's $\alpha$ $\geq 0.70)^{81}$

We will assess the prevalence of adjustment disorders according to International Classification of Diseases-11 (ICD-11) in patients and caregivers using the new Adjustment Disorder Module of the Composite International Diagnostic Interview. ${ }^{82}$ The structured interview measures the disorder according to the revised conceptualisation in the ICD-11. If participants name one or more stressful events during the past 12 months, they are asked about accompanying symptoms, duration of symptoms and impairments in their professional or social life. The diagnosis will be determined according to the criteria described by Perkonigg and colleagues. ${ }^{82}$

We will assess the desire for hastened death in patients using the short form of the Schedule of Attitudes Toward Hastened Death ${ }^{83}$ The six-item version of the original instrument ${ }^{84}$ measures a wish to die sooner than might occur by natural disease. Items are scored with either being true (1) or false $(0)$. For the total score, we count the number of endorsed items, ranging from 0 to 6 . High scores indicate high levels of desire for hastened death. We selected the six relevant items out of the validated German version. ${ }^{85}$ The short version showed good internal consistency (Cronbach's $\alpha=0.83){ }^{83}$

We will assess suicidal ideation in patients and caregivers using the Beck Scale for Suicidal Ideation. ${ }^{86} 87$ The 21-item scale measures the intensity of suicidal tendencies with three statements for each item (eg, $0=\mathrm{I}$ have a moderate to strong wish to live, $1=\mathrm{I}$ have a weak wish to live and $2=\mathrm{I}$ have no wish to live). The first five items can be used to screen for suicidal ideation. If items 4 and 5, measuring active and passive suicidal ideation, are scored with 0 , participants are asked to skip to the items regarding previous suicidal attempts. The sum score ranges from 0 to 38 for the total scale and from 0 to 10 for the screening score. Higher values indicate stronger suicidal tendencies. The German version showed high internal consistency for the screening items (Cronbach's $\alpha=0.89$ ) and the total scale (Cronbach's $\alpha=0.88$ ). ${ }^{87}$

We will assess complicated grief in caregivers after the patient's death using the Inventory of Complicated Grief..$^{88}$ The 19-item scale measures symptoms of complicated grief on based on the originally proposed criteria for DSM $-5^{80}$ on a single factor. Items are scored on a 5-point Likert scale ranging from 0 (never) to 4 (always). The sum score ranges from 0 to 76 . Scores $\geq 25$ indicate experiences of complicated grief. The German version of the scale showed good internal consistency (Cronbach's $\alpha=0.87){ }^{89}$

We will assess the quality of dying and death from the caregivers' perspective using the Quality of Dying and Death Questionnaire. ${ }^{90}$ After a patient's death, the questionnaire is usually administered as an interview, asking caregivers to evaluate the patients' dying experience during their last 7 days or last month. In this study, we will administer a short 20 -item version ${ }^{91}$ as a self-report instrument. Caregivers indicate how they would rate each experience for the patient on a scale from 0 (terrible experience) to 10 (almost perfect experience). The score is calculated by adding up the ratings and dividing them by the number of items answered. To obtain a total score between 0 and 100 , the result is multiplied by 10 . Higher scores indicate a better quality of the dying experience. The adapted German version showed good internal consistency (Cronbach's $\alpha=0.85) .{ }^{92}$

\section{Symptom burden and resources}

We will assess symptom burden in patients using the Memorial Symptom Assessment Scale. ${ }^{93}$ The 28-item scale measures the frequency and the distress of physical symptoms that may occur as a result of cancer or its treatment. Items are scored on a five-point Likert scale ranging from 0 (not at all distressed) to 4 (very much distressed). For the total score, we count the number of physical symptoms 
reported by the patients. The scale showed good internal consistency (Cronbach's $\alpha=0.87$ ).

We will assess self-reported symptoms of depression and anxiety in patients and caregivers using the Patient Health Questionnaire ${ }^{94}$ and the Generalized Anxiety Disorder Questionnaire. ${ }^{95}$ Both instruments measure symptoms of depression and anxiety based on DSM-5 criteria. Items are scored on a 4-point Likert scale ranging from 0 (not at all) to 3 (nearly every day). Sum scores range from 0 to 27 and 0 to 21, respectively. Scores $\geq 10$ indicate moderate, scores $\geq 15$ severe depression or anxiety. Both German versions showed good internal consistency (Cronbach's $\alpha=0.89){ }^{96} 97$

We will assess meaning in life and crisis of meaning in patients and caregivers using the subscales of the Sources of Meaning and Meaning in Life Questionnaire. ${ }^{98}$ The fiveitem subscales measure perceived meaningful fulfilment and crisis of meaning. Items are scored on a 6-point Likert scale ranging from 0 (totally disagree) to 5 (totally agree). Sum scores for each subscale range from 0 to 25 . Higher scores indicate a greater sense of meaningfulness or a greater lack of meaning, respectively. Both scales showed acceptable to good internal consistency (Cronbach's $\alpha=0.72$ to 0.87 ).

\section{Support needs}

We will assess the need for and utilisation of psychosocial support for existential distress in patients and caregivers using a standardised self-report questionnaire. It measures whether participants are still thinking about the existential concerns mentioned in the overall questionnaire, including fear of death and dying, fear of suffering, sense of pointlessness or hopelessness, sense of loss of dignity, preparation for the end of life, anticipatory grief and existential loneliness. It will further assess whether participants wish to receive support dealing with this subject and who would be their preferred source of support (partner, family, friends, treating physician, psychologist/ psychotherapist, other patients or caregivers). Moreover, participants will be asked whether they have previously used psychosocial support services.

\section{Statistical methods \\ Power calculation}

To determine the relative risk for a binary end-of-life outcome after 12 months, we base our sample size calculation on a multiple logistic regression model. The model includes existential distress at baseline and the covariates age, gender and socioeconomic status. Because the test statistic in logistic regression analysis is based on a $\chi^{2}$ distribution, the number of degrees of freedom (df) is equal to the number of regression weights in the model. Accordingly, we calculate the required sample size to reliably estimate the model by multiplying the minimum number of observations needed per df $(n=15)$ with the number of $\mathrm{df}(\mathrm{df}=4)$ and dividing the product by the ratio of positive events expected for the binary outcomes. ${ }^{99}$ To predict receipt of aggressive treatment, we use the mean frequency reported by the German studies of Dasch $e t a b^{2}$ $(38 \%)$ and Radbruch et a $\tilde{l}^{53}(10 \%)$. Thus, we require a sample of $n=\frac{15 * 4}{0.24}=250$ for our analyses at 12-month follow-up. Based on previous experiences, we expect a drop-out rate of $50 \%$ due to death or loss of interest in participation ${ }^{100}$ resulting in a required sample size of $\mathrm{n}=500$ at baseline.

\section{Statistical analysis}

We will calculate descriptive statistics to determine sample and medical characteristics as well as the prevalence of existential distress, mental disorders and palliative care outcomes. We will estimate frequencies with $95 \%$ CIs. To analyse the impact of existential distress at baseline on binary and continuous end-of-life and palliative care outcomes after 12 months, we conduct multiple linear and logistic regression. After testing for multicollinearity, we will control for demographic, physical and psychosocial variables. Analyses will be conducted separately for patients and caregivers.

We will analyse the longitudinal trajectory of existential distress across the 12-month study period using growth mixture models. These models estimate distinct groups of existential distress trajectories based on a structural equation modelling framework. The expected longitudinal dropout of patients with a prognosis of less than 12 months will be handled by full information maximum likelihood estimation. ${ }^{101}$ We will use latent class analysis to explore whether the measured existential concerns form distinct types of existential distress. If more than $5 \%$ of the observed values are missing, we will replace missing data using multiple imputation. Existential distress may be higher among caregivers of patients who are physically too weak to participate and close to death. We will account for this effect by including patient participation as a control variable in caregiver models. We will perform statistical analyses in IBM SPSS Statistics, version $27,{ }^{102}$ and RStudio 1.4 with R 4.0.5. ${ }^{103} 104$

\section{Patient and public involvement}

The research questions and outcome measures are based on previous findings on concerns of patients with advanced cancer and their caregivers as well as patientcentred and caregiver-centred healthcare outcomes. Patients or the public were not involved in the design of the study. Patients and their caregivers are involved through completion of self-report questionnaires and interviews. We inform patients and caregivers that they are provided with the study results on request.

\section{Ethics and dissemination}

The study was approved by the institutional research ethics committee (Lokale Psychologische Ethikkommission am Zentrum für Psychosoziale Medizin, reference number LPEK-0177). Informed consent will be obtained from all individual participants included in the study or their legal guardians. All procedures performed in this study are in accordance with the 1964 Helsinki Declaration 
and its later amendments. Results of this study will be presented at scientific conferences and published in peer-reviewed journals. Other forms of dissemination will include sharing results on the psychometric properties of the structured demoralisation interview with international research groups to further examine demoralisation as a diagnostic category as proposed by Kissane and colleagues. ${ }^{74}$ Dissemination will further include communication with healthcare professionals providing psychosocial treatment for patients and caregivers. Study progress will be regularly updated on ClinicalTrials.gov.

\section{Strengths and limitations}

This longitudinal study will provide unique systematic knowledge about patients' and caregivers' existential concerns. The empirical data will allow for conclusions concerning frequency and course of existential distress throughout 1 year. There is a need for quantitative studies focusing explicitly on existential concerns of caregivers who are sometimes referred to as 'hidden patients' because their distress tends to be overlooked. ${ }^{105}$ The recruitment strategy will allow enrolment of a large, heterogeneous sample of patients with advanced cancer from a range of clinics and treatment facilities. Limitations include potentially high dropout rates due to patients' physical decline or death within the study period. Heterogeneous patient and caregiver samples will limit subgroup-specific interpretations. Despite these limitations, the extensive assessment of psychological distress in a potentially highly distressed and understudied sample will contribute to the recognition of existential distress in patients and caregiver populations and to development of targeted interventions. Profiles of existential distress may be applied by clinicians from multiple professions and help to address existential concerns effectively.

Acknowledgements We would like to thank David Kissane and Irene Bobevski for their valuable support regarding the assessment protocol.

Contributors SV, MH, CB, KO and UK designed the study and coordinate the research project. RP, AK and SV wrote the first draft of the manuscript. $\mathrm{MH}, \mathrm{CB}, \mathrm{KO}$ and UK revised it critically for important intellectual content. All authors approved the final version of the manuscript and agree to be accountable for all aspects of the study.

Funding This work is funded by the Max-Eder junior research group program of the German Cancer Aid (grant number 70113404).

Competing interests None declared.

Patient and public involvement Patients and/or the public were not involved in the design, or conduct, or reporting, or dissemination plans of this research.

Patient consent for publication Not required.

Provenance and peer review Not commissioned; externally peer reviewed.

Open access This is an open access article distributed in accordance with the Creative Commons Attribution Non Commercial (CC BY-NC 4.0) license, which permits others to distribute, remix, adapt, build upon this work non-commercially, and license their derivative works on different terms, provided the original work is properly cited, appropriate credit is given, any changes made indicated, and the use is non-commercial. See: http://creativecommons.org/licenses/by-nc/4.0/.

\section{ORCID iDs}

Rebecca Philipp http://orcid.org/0000-0002-1875-3823

Martin Härter http://orcid.org/0000-0001-7443-9890

Carsten Bokemeyer http://orcid.org/0000-0001-6071-7810
Karin Oechsle http://orcid.org/0000-0002-5183-641X

Sigrun Vehling http://orcid.org/0000-0001-9314-4326

\section{REFERENCES}

1 Henley SJ, Thomas CC, Lewis DR, et al. Annual report to the nation on the status of cancer, part II: progress toward healthy people 2020 objectives for 4 common cancers. Cancer 2020;126:2250-66.

2 Barnes B, Kraywinkel K, Nowossadeck E. Bericht zum Krebsgeschehen in Deutschland 2016, 2016. Available: https:// edoc.rki.de/handle/176904/3264

3 Mehnert A, Brähler E, Faller $\mathrm{H}$, et al. Four-week prevalence of mental disorders in patients with cancer across major tumor entities. JCO 2014;32:3540-6.

4 Mitchell AJ, Chan M, Bhatti $\mathrm{H}$, et al. Prevalence of depression, anxiety, and adjustment disorder in oncological, haematological, and palliative-care settings: a meta-analysis of 94 interview-based studies. Lancet Oncol 2011;12:160-74.

5 Areia NP, Fonseca G, Major S, et al. Psychological morbidity in family caregivers of people living with terminal cancer: prevalence and predictors. Palliat Support Care 2019;17:1-8.

6 Costa-Requena G, Cristófol R, Cañete J. Caregivers' morbidity in palliative care unit: predicting by gender, age, burden and selfesteem. Support Care Cancer 2012;20:1465-70.

7 Williams A-L, McCorkle R. Cancer family caregivers during the palliative, hospice, and bereavement phases: a review of the descriptive psychosocial literature. Palliat Support Care 2011;9:315-25.

8 Ullrich A, Ascherfeld L, Marx G, et al. Quality of life, psychological burden, needs, and satisfaction during specialized inpatient palliative care in family caregivers of advanced cancer patients. BMC Palliat Care 2017;16:31.

9 Saunders CM. The management of terminal malignant disease. 2nd edn. London: Edward Arnold, 1984.

10 Cassel EJ. The nature of suffering and the goals of medicine. N Engl J Med 1982;306:639-45.

11 Weisman AD, Worden JW. The existential plight in cancer: significance of the first 100 days. Int J Psychiatry Med 1977;7:1-15.

12 Grech A, Marks A. Existential suffering part 1: definition and diagnosis \#319. J Palliat Med 2017;20:93-4.

13 Vehling S, Kissane DW. Existential distress in cancer: alleviating suffering from fundamental loss and change. Psychooncology 2018;27:2525-30.

14 Breitbart W. Spirituality and meaning in supportive care: spiritualityand meaning-centered group psychotherapy interventions in advanced cancer. Support Care Cancer 2002;10:272-80.

15 LeMay K, Wilson K. Treatment of existential distress in life threatening illness: a review of manualized interventions. Clin Psychol Rev 2008;28:472-93.

16 Best M, Aldridge L, Butow P, et al. Conceptual analysis of suffering in cancer: a systematic review. Psychooncology 2015;24:977-86.

17 Kissane DW. The relief of existential suffering. Arch Intern Med 2012;172:1501-5.

18 Henoch I, Danielson E. Existential concerns among patients with cancer and interventions to meet them: an integrative literature review. Psychooncology 2009;18:225-36.

19 Boston P, Bruce A, Schreiber R. Existential suffering in the palliative care setting: an integrated literature review. J Pain Symptom Manage 2011;41:604-18.

20 Cherny NI, Coyle N, Foley KM. Suffering in the advanced cancer patient: a definition and taxonomy. J Palliat Care 1994;10:57-70.

21 Krause S, Rydall A, Hales S, et al. Initial validation of the death and dying distress scale for the assessment of death anxiety in patients with advanced cancer. J Pain Symptom Manage 2015;49:126-34.

22 Lo C, Hales S, Zimmermann C, et al. Measuring death-related anxiety in advanced cancer: preliminary psychometrics of the death and dying distress scale. J Pediatr Hematol Oncol 2011;33:140-5.

23 Kissane DW, Clarke DM, Street AF. Demoralization syndrome - a relevant psychiatric diagnosis for palliative care. J Palliat Care 2001;17:12-21.

24 Lo C, Panday T, Zeppieri J, et al. Preliminary psychometrics of the Existential distress scale in patients with advanced cancer. Eur J Cancer Care 2017;26:e12597.

25 Chochinov HM, Hack T, Hassard T, et al. Dignity in the terminally ill: a cross-sectional, cohort study. Lancet 2002;360:2026-30.

26 Grass L, de Figueiredo JM, de FJM. Advances in the understanding of demoralization in oncology and palliative care. Psycho-Oncol. 2018;12:99-108. 
27 Robinson S, Kissane DW, Brooker J, et al. A systematic review of the demoralization syndrome in individuals with progressive disease and cancer: a decade of research. J Pain Symptom Manage 2015;49:595-610.

28 Tecuta L, Tomba E, Grandi S, et al. Demoralization: a systematic review on its clinical characterization. Psychol Med 2015;45:673-91.

29 Vehling S, Malfitano C, Shnall J, et al. A concept map of deathrelated anxieties in patients with advanced cancer. BMJ Support Palliat Care 2017;7:427-34.

30 Chochinov HM, Kristjanson LJ, Hack TF, et al. Burden to others and the terminally ill. J Pain Symptom Manage 2007;34:463-71.

31 Vehling S, Mehnert A. Symptom burden, loss of dignity, and demoralization in patients with cancer: a mediation model. Psychooncology 2014;23:283-90.

32 Wentlandt K, Burman D, Swami N, et al. Preparation for the end of life in patients with advanced cancer and association with communication with professional caregivers. Psychooncology 2012;21:868-76.

33 Morita T, Kawa M, Honke Y, et al. Existential concerns of terminally ill cancer patients receiving specialized palliative care in Japan. Support Care Cancer 2004;12:137-40.

34 Applebaum AJ, Farran CJ, Marziliano AM, et al. Preliminary study of themes of meaning and psychosocial service use among informal cancer caregivers. Pall Supp Care 2014;12:139-48.

35 Stenberg U, Ruland CM, Miaskowski C. Review of the literature on the effects of caring for a patient with cancer. Psychooncology 2010;19:1013-25.

36 Eifert EK, Adams R, Dudley W, et al. Family caregiver identity: a literature review. Am J Health Educ 2015;46:357-67.

37 Reblin M, Small B, Jim H, et al. Mediating burden and stress over time: caregivers of patients with primary brain tumor. Psychooncology 2018;27:607-12.

38 Nielsen MK, Neergaard MA, Jensen AB, et al. Preloss grief in family caregivers during end-of-life cancer care: a nationwide population-based cohort study. Psychooncology 2017;26:2048-56.

39 Applebaum AJ, Kryza-Lacombe M, Buthorn J, et al. Existential distress among caregivers of patients with brain tumors: a review of the literature. NOPRAC 2016;3:232-44.

40 Badr H, Smith CB, Goldstein NE, et al. Dyadic psychosocial intervention for advanced lung cancer patients and their family caregivers: results of a randomized pilot trial. Cancer 2015;121:150-8.

41 Badr H, Taylor CLC. Social constraints and spousal communication in lung cancer. Psychooncology 2006;15:673-83.

42 Manne S, Badr H. Intimacy and relationship processes in couples psychosocial adaptation to cancer. Cancer 2008;112:2541-55.

43 Philipp R, Mehnert A, Müller V, et al. Perceived relatedness, death acceptance, and demoralization in patients with cancer. Support Care Cancer 2020;28:2693-700.

44 Chiu Y-W, Huang C-T, Yin S-M, et al. Determinants of complicated grief in caregivers who cared for terminal cancer patients. Support Care Cancer 2010;18:1321-7.

45 Lobb EA, Kristjanson LJ, Aoun SM, et al. Predictors of complicated grief: a systematic review of empirical studies. Death Stud 2010;34:673-98.

46 Mystakidou K, Tsilika E, Parpa E. Caregivers of advanced cancer patients: feelings of hopelessness and depression. Cancer Nurs 2007;30:412-8.

47 Fang C-K, Chang M-C, Chen P-J, et al. A correlational study of suicidal ideation with psychological distress, depression, and demoralization in patients with cancer. Support Care Cancer 2014;22:3165-74.

48 Robinson S, Kissane DW, Brooker J, et al. The relationship between poor quality of life and desire to hasten death: a multiple mediation model examining the contributions of depression, demoralization, loss of control, and low self-worth. J Pain Symptom Manage 2017;53:243-9.

49 Vehling S, Kissane DW, Lo C, et al. The association of demoralization with mental disorders and suicidal ideation in patients with cancer. Cancer 2017;123:3394-401.

50 Li M, Watt S, Escaf M, et al. Medical assistance in dying implementing a hospital-based program in Canada. N Engl J Med 2017;376:2082-8.

51 Lichtenthal WG, Nilsson M, Zhang B, et al. Do rates of mental disorders and existential distress among advanced stage cancer patients increase as death approaches? Psychooncology 2009;18:50-61.

52 Dasch B, Kalies H, Feddersen B, et al. Care of cancer patients at the end of life in a German university hospital: a retrospective observational study from 2014. PLoS One 2017;12:e0175124.
53 Radbruch L, Andersohn F, Walker J. Palliative care: oversupply curative-undersupply palliative? analysis of selected treatments at the end of life. Bertelsmann Foundation, 2015. Available: https:// www.bertelsmann- stiftung.de/fileadmin/files/BSt/Publikationen/ GrauePublikationen/Studie_VV_FCG_Ueber- Unterversorgungpalliativ.pdf [Accessed $8 \mathrm{Apr}$ 2018].

54 Steinhauser KE, Fitchett G, Handzo GF, et al. State of the science of spirituality and palliative care research Part I: definitions, measurement, and outcomes. J Pain Symptom Manage 2017;54:428-40.

55 Phelps AC, Maciejewski PK, Nilsson M. Religious coping and use of intensive life-prolonging care near death in patients with advanced cancer. JAMA 2009;301:1140-7.

56 Greer JA, Jacobs JM, El-Jawahri A. Role of patient coping strategies in understanding the effects of early palliative care on quality of life and mood. J Clin Oncol 2017:JCO2017737221.

57 Nipp RD, Greer JA, El-Jawahri A, et al. Coping and prognostic awareness in patients with advanced cancer. JCO 2017;35:2551-7.

58 Applebaum AJ, Stein EM, Lord-Bessen J, et al. Optimism, social support, and mental health outcomes in patients with advanced cancer. Psychooncology 2014;23:299-306.

59 Boston PH, Mount BM. The Caregiver's Perspective on Existential and Spiritual Distress in Palliative Care. J Pain Symptom Manage 2006;32:13-26.

60 Bates AT. Addressing existential suffering. BC Med J 2016;58:268-73

61 Engelmann D, Scheffold K, Friedrich M, et al. Death-related anxiety in patients with advanced cancer: validation of the German version of the death and dying distress scale. J Pain Symptom Manage 2016;52:582-7.

62 Robinson S, Kissane DW, Brooker J, et al. Refinement and revalidation of the demoralization scale: the DS-II-internal validity. Cancer 2016;122:2251-9.

63 Robinson S, Kissane DW, Brooker J, et al. Refinement and revalidation of the demoralization scale: the DS-II-external validity. Cancer 2016;122:2260-7.

64 Kissane DW, Wein S, Love A, et al. The Demoralization scale: a report of its development and preliminary validation. J Palliat Care 2004;20:269-76.

65 Mehnert A, Vehling S, Höcker A, et al. Demoralization and depression in patients with advanced cancer: validation of the German version of the demoralization scale. J Pain Symptom Manage 2011;42:768-76.

66 Blatt SJ, D'Afflitti JP, Quinlan DM. Experiences of depression in normal young adults. J Abnorm Psychol 1976;85:383-9.

67 Blatt SJ, Zohar AH, Quinlan DM, et al. Subscales within the dependency factor of the depressive experiences questionnaire. J Pers Assess 1995;64:319-39.

68 Blatt SJ, Quinlan DM, Chevron ES, et al. Dependency and selfcriticism: psychological dimensions of depression. J Consult Clin Psychol 1982;50:113-24.

69 Beutel ME, Wiltink J, Hafner C. Dependence and self-criticism as a psychological dimension of depression: validation of the Germanlanguage version of the depressive experience questionnaire (DEQ). Zeitschrift für klinische Psychologie, Psychiatrie und Psychotherapie 2004;52:1-14.

70 Krieger T, Zimmermann J, Beutel ME, et al. Ein Vergleich verschiedener Kurzversionen des depressive experiences questionnaire (DEQ) Zur Erhebung von Selbstkritik und Abhängigkeit. Diagnostica 2014;60:126-39.

71 Vehling S, Gerstorf D, Schulz-Kindermann F, et al. The daily dynamics of loss orientation and life engagement in advanced cancer: a pilot study to characterise patterns of adaptation at the end of life. Eur J Cancer Care 2018;27:e12842.

72 Chochinov HM, Hassard T, McClement S, et al. The patient dignity inventory: a novel way of measuring dignity-related distress in palliative care. J Pain Symptom Manage 2008;36:559-71.

73 Sautier LP, Vehling S, Mehnert A. Assessment of patients' dignity in cancer care: preliminary psychometrics of the German version of the patient dignity inventory (PDI-G). J Pain Symptom Manage 2014;47:181-8.

74 Kissane DW, Bobevski I, Gaitanis P, et al. Exploratory examination of the utility of demoralization as a diagnostic specifier for adjustment disorder and major depression. Gen Hosp Psychiatry 2017;46:20-4

75 El-Jawahri A, Forst D, Fenech A. Relationship between perceptions of treatment goals and psychological distress in patients with advanced cancer. J Natl Compr Canc Netw 2020;18:849-55.

76 Marwit SJ, Meuser TM. Development of a short form inventory to assess grief in caregivers of dementia patients. Death Stud 2005;29:191-205. 
77 Losada A, Márquez-González M, Peñacoba C, et al. Development and validation of the caregiver guilt questionnaire. Int Psychogeriatr 2010;22:650-60.

78 Earle CC, Park ER, Lai B, et al. Identifying potential indicators of the quality of end-of-life cancer care from administrative data. J Clin Oncol 2003;21:1133-8.

79 First MB, Williams JBW, Karg RS. Structured clinical interview for DSM-5 disorders: SCID-5-CV clinician version. Arlington, VA: American Psychiatric Association Publishing, 2016.

80 American Psychiatric Association. Diagnostic and statistical manual of mental disorders (5th ED): DSM-5. 5th edn. Washington DC: American Psychiatric Association, 2013.

81 Beesdo-Baum K, Zaudig M, Wittchen H-U. Strukturiertes Klinisches interview für DSM-5®-Störungen - Klinische version. Göttingen: Hogrefe, 2019.

82 Perkonigg A, Lorenz L, Maercker A. Prevalence and correlates of ICD-11 adjustment disorder: findings from the Zurich adjustment disorder study. Int J Clin Health Psychol 2018;18:209-17.

83 Kolva E, Rosenfeld B, Liu Y, et al. Using item response theory (irt) to reduce patient burden when assessing desire for hastened death. Psychol Assess 2017;29:349-53.

84 Rosenfeld B, Breitbart W, Galietta M. The schedule of attitudes toward hastened death: measuring desire for death in terminally ill cancer patients. Cancer 2000;88:2868-75.

85 Galushko M, Strupp J, Walisko-Waniek J, et al. Validation of the German version of the schedule of attitudes toward Hastened death (SAHD-D) with patients in palliative care. Pall Supp Care 2015;13:713-23.

86 Beck AT, Steer RA. Beck scale for suicide ideation (BSS). Bloomington: Pearson, 1993.

87 Kliem S, Brähler E. Beck-Suizidgedanken-Skala (BSS). Frankfurt am Main: Pearson Assessment, 2015.

88 Prigerson HG, Maciejewski PK, Reynolds CF, et al. Inventory of complicated grief: a scale to measure maladaptive symptoms of loss. Psychiatry Res 1995;59:65-79.

89 Lumbeck G, Brandstätter M, Geissner E. Erstvalidierung der deutschen Version des "Inventory of Complicated Grief" (ICG-D). Zeitschrift für Klinische Psychologie und Psychotherapie 2012;41:243-8.

90 Curtis JR, Patrick DL, Engelberg RA. A measure of the quality of dying and death. initial validation using after-death interviews with family members. J Pain Symptom Manag 2002;24:17-31.
91 Mah K, Hales S, Weerakkody I. Measuring the quality of dying and death in advanced cancer: item characteristics and factor structure of the quality of dying and death questionnaire. Palliat Med 2018.

92 Heckel M, Bussmann S, Stiel S, et al. Validation of the German version of the quality of dying and death questionnaire for informal caregivers (QODD-D-Ang). J Pain Symptom Manage 2015;50:402-13.

93 Chang VT, Hwang SS, Feuerman M, et al. The Memorial symptom assessment scale short form (MSAS-SF). Cancer 2000;89:1162-71.

94 Kroenke K, Spitzer RL, Williams JB. The PHQ-9: validity of a brief depression severity measure. J Gen Intern Med 2001;16:606-13.

95 Spitzer RL, Kroenke K, Williams JBW, et al. A brief measure for assessing generalized anxiety disorder. Arch Intern Med 2006;166:1092-7.

96 Löwe B, Spitzer RL, Gräfe K. Comparative validity of three screening questionnaires for DSM-IV depressive disorders and physicians? diagnoses. J Affect Disord 2004;78:131-40.

97 Löwe B, Decker O, Müller S, et al. Validation and standardization of the generalized anxiety disorder screener (GAD-7) in the general population. Med Care 2008;46:266-74.

98 Schnell T, Becker P. LEBE - Fragebogen zu Lebensbedeutungen und Lebenssinn. Göttingen: Hogrefe, 2007.

99 Dupont WD, Plummer WD. Power and sample size calculations. A review and computer program. Control Clin Trials 1990;11:116-28.

100 Spangenberg L, Zenger M, Garcia-Torres F, et al. Dimensionality, stability, and validity of the Beck Hopelessness scale in cancer patients receiving curative and palliative treatment. J Pain Symptom Manage 2016;51:615-22.

101 Asendorpf JB, van de Schoot R, Denissen JJA, et al. Reducing bias due to systematic attrition in longitudinal studies: the benefits of multiple imputation. Int J Behav Dev 2014;38:453-60.

102 IBM Corp. Ibm SPSS statistics for windows, version 25.0. Armonk, NY: IBM Corp, 2017.

103 RStudio Team. RStudio: integrated development for R. Boston, MA: RStudio, Inc, 2016.

104 R Core Team. R: a language and environment for statistical computing. Vienna, Austria: R Foundation for Statistical Computing, 2019.

105 Hoerger M, Cullen BD. Early Integrated Palliative Care and Reduced Emotional Distress in Cancer Caregivers: Reaching the "Hidden Patients". Oncologist 2017;22:1419-20. 